\title{
Is it the time to implement the routine use of distress thermometer among Egyptian patients with newly diagnosed cancer?
}

Nashwa Abd El-Aziz ${ }^{1,2}$, Salah Khallaf', Waleed Abozaid ${ }^{3}$, Ghada Elgohary ${ }^{2,4}$, Ola Abd El-Fattah ${ }^{4,5}$, Mai Alhawari ${ }^{2}$, Safaa Khaled ${ }^{6}$, Azza AbdelHaffez ${ }^{7}$, Ehab Kamel ${ }^{8}$ and Sherif Mohamed ${ }^{9 *}$ (i)

\begin{abstract}
Background: The distress thermometer (DT) is an effective tool for identifying distress among cancer patients worldwide. However, DT has not been studied in Egyptian patients. We aimed to study the prevalence of distress among Egyptian patients with different types of cancers using DT.

Methods: A total of 550 patients with newly diagnosed hematological and solid cancers who were followed up at 3 Oncology Centers in Egypt were enrolled. They completed a sociodemographic and clinical status questionnaire, the DT and the Problem List (PL) scale.

Results: At a DT cut-off score of $\geq 4,46 \%$ of patients had significant distress, which was related to the tumor site and stage. The most frequent problems reported were treatment decision (64.4\%), worry (47\%), and fears (44.5\%). In univariate logistic regression analysis, participants who had significant distress described 23 out of 36 problems in the practical, family, emotional, and physical areas. After adjustment to sociodemographic and clinical characteristics, multivariable analysis confirmed that insurance, depression, fear, sadness, worry, loss of interest in usual activity, and sleep were independent factors associated with significant distress in cancer patients.

Conclusions: Almost half of Egyptian patients newly diagnosed with cancer reported significant distress. Those who had significant distress described extra problems in the practical, family, emotional, and physical areas. We recommend the routine use of DT for screening Egyptian patients with cancer, as well as the involvement of the psycho-oncology and social services, at the time of their initial diagnosis.
\end{abstract}

Keywords: Cancer, Distress thermometer, Egypt, New, Screening

\section{Background}

Cancer is a leading cause of morbidity and mortality worldwide. In a recent study from Egypt [1], agestandardized incidence rates per 100,000 for cancer were 175.9, 157.0, and 166.6 for males, females, and both sexes, respectively. The commonest sites for cancer were; liver (33.6\%) and bladder (10.7\%) among men,

\footnotetext{
* Correspondence: saawm220@gmail.com

${ }^{9}$ Department of Chest Diseases and Tuberculosis, Faculty of Medicine, Assiut University, Assiut, Egypt

Full list of author information is available at the end of the article
}

breast (32.0\%) and liver (13.5\%) among women, and liver (23.8\%), breast (15.4\%), and bladder (6.9\%) for both sexes, respectively. By 2050, a 3-fold increase in incident cancer relative to 2013 is expected [1]. The National Comprehensive Cancer Network (NCCN) defines distress as an emotionally unpleasant psychological (cognitive, behavioral, emotional), social, and/or spiritual experience that might interfere with a patient's ability to effectively cope with cancer, its physical symptoms, and its treatment [2]. Unfortunately, distress is quite common among cancer patients, with a reported clinically 
significant distress to be between 20 and $47 \%$ during course of the disease [3]. Negative impacts of high levels of distress on cancer patients include less adherence to treatment plans, dissatisfaction with overall care, poorer quality of life, and even poorer survival rates $[4,5]$. Because of these drawbacks, it is thought that systematic screening of patients for distress is the effective way that allows timely support for those who are most in need [6, 7]. Therefore, it is not surprising to find that many international regulatory organizations and professional societies [3, 8, 9], have recommended the routine screening and management of distress as an integral aspect of whole-person cancer care.

Then, the onco-medical team taking care of cancer patients has to carry out screening their patients starting with the selection of a screening tool that is suitable in terms of briefness, precision, and acceptability $[7,8]$. Being a quick, easy and valid instrument to recognize, diagnose and provide prompt management of distress in cancer patients, the distress thermometer (DT) represents the ideal screening tool in that regards. Review of the literature had shown that DT has been investigated and validated as an effective screening tool for detecting distress among patients with various types of cancer, such as prostate carcinoma [10], lung cancer [11], and breast cancer [12]. Moreover, the original NCCN English version [13] has been successfully translated into several languages, including Dutch [14], Japanese [15], Turkish [16], Italian, Spanish and Portuguese [17], and recently its Arabic version has been validated in Saudi cancer patients [18].

To the best of our knowledge, the DT has not been studied in Egyptian patients with cancer. Therefore, the aims of this study were to study the prevalence of emotional distress among Egyptian patients with different types of cancers at their initial diagnosis, to evaluate the value of implementing the DT as screening tool in those patients, and to identify the most significant factors of the DT problem list (PL) that account for such distress. Identification of such distress and its subsequent management may improve the patients' outcomes and quality of life.

\section{Methods}

\section{Study population}

An ethical approval was obtained from the Institutional Review Committee of South Egypt Cancer Institute (No: 483). Egyptian cancer patients who have been newly diagnosed with different types of hematological malignancies and/or solid cancers and consulted one of the three Oncology Centers (South Egypt Cancer Institute (SECI), Assiut University Hospital (AUH), and Mansura University Hospital (MUH) were enrolled into the study. Also, the study enrolled some referred lung cancer patients to the Oncology Department of either AUH or SECI.
Eligible patients were Egyptian adults ( $\geq 18$ years old), of both genders, who had confirmed diagnosis of cancer (either hematological or solid malignancy), with an adequate command of speaking and reading the Arabic language, with an Eastern Cooperative Oncology Group (ECOG) performance status of $<3$, and gave an informed consent. Patients having history of, or undergoing treatment for psychiatric illness were excluded.

\section{Sociodemographic data and medical status}

The patients' sociodemographic and clinical features were retrieved from the patients' medical records. Standard sociodemographic data were collected including age, marital status, education level, employment status, performance status, type and stage of cancer as defined by the TNM classification system, and the type of treatment will be received.

\section{Distress thermometer (DT)}

The recently validated Arabic version of DT [18] was used for screening patients of the current study for distress with a cut-off score of $\geq 4$ for significant distress. The study objectives and procedure were fully explained to the eligible patients. Screening was carried out for newly diagnosed patients with cancer at their first out-patient visit or inpatient admission. Patients were asked to rate their distress in the past week on an 11-point visual analog scale ranging from 0 (no distress) to 10 (extreme distress) [18]. Patients were then asked to fill in the Problem List (PL) that accompanies the visual image of the DT to check whether or not (yes/no) they have any of the problems listed during the previous 7 days $[2,18]$. For patients who are illiterate, a research assistant helped the patient to rate their distress and fill in the PL. This PL consisted of 36 problems of five grouped categories; spiritual/religious concerns, practical problems, family problems, emotional problems, and physical problems. Correlation between the PL and DT was carried out to identify the nature of the distress and related factors.

\section{Statistical analysis}

The Statistical Package for Social Science; SPSS, version 22 (SPSS Inc., Chicago, IL, USA) has been used for data analysis. The mean score, the standard deviation, the median score and the frequency distribution of the DT have been explored using descriptive statistical analysis. All $P$-values were two-tailed. A P-value $<0.05$ was considered statistically significant. Binary logistic regression test was carried out to explore the association between the DT cut-off scores of 4 [18] and the demographic and clinical variables, while binary and multivariable logistic regression tests were used to analyse the association between the DT cut-off scores and individual items in the PL. 


\section{Results}

\section{Sociodemographic and clinical characteristics}

A total of 550 patients participated in the current study. The median age was 55 (range 18-85) years. Females constituted $60 \%$ of the participants. Three hundred thirty-three $(79 \%)$ patients scored two or less on the ECOG performance status. Different types of solid and hematological malignancies were included; the majority were solid tumors (465/550, 85\%) versus 85/550,15\% hematological malignancies. Among the solid tumors, the most common types were breast cancer (32.7\%), gastrointestinal cancers (23\%), and genitourinary (13\%). Despite that all patients were newly diagnosed with cancer, $56 \%$ of them had stage IV at presentation. Forty-one percent of patients had associated medical comorbidities. Table 1 details the demographic data of the study cohorts.

Data from distress thermometer and problem list analysis Two hundred fifty-four (46.2\%) patients had significant distress (DT cut off score $\geq 4$ ). The patients' average DT score was 3.7. There were significant differences between patients with significant distress (DT cut off score $\geq 4$ ) and those without significant one; with regards to age $(p<0.001)$, gender $(p<0.001)$, educational level $(p=$ $0.013)$, tumor site $(p=0.006)$, and stage of the disease $(p=0.001)$. Table 1 shows these differences. The most frequent problems reported on the practical domain of the PL were, in descending order, treatment decision $(64.4 \%)$, worry (47\%), fears (44.5\%), and pain $(42.2 \%)$. Table 2 shows these details.

\section{Association between significant DT score and the PL items}

Binary logistic regression showed that DT score of 4 or more was found to have a statistically significant correlation with most of the PL items including; insurance, family health issue, depression, fear, nervousness, sadness, worry, loss of interest in usual activity, religious concerns, appearance, bathing and dressing, breathing, diarrhea, fatigue, feeling swollen, fever, getting around, indigestion, mouth sores, nausea, pain, substance abuse, and sleep. After adjustment to sociodemographic and clinical characteristics, multivariable analysis confirmed that insurance, depression, fear, sadness, worry, loss of interest in usual activity, and sleep, were independent factors associated with significant distress in cancer patients. Table 3 details these associations.

\section{Discussion}

To the best of our knowledge, this is the first study that evaluates the problem of emotional distress among a large number of newly diagnosed patients with different types of cancer, attending three University cancer centers in Egypt.

Using the Arabic version of DT [18] we identified that $46 \%$ of our cancer patients had significant distress, which was significantly related to age, gender, educational level, tumor site, advanced stage of the disease, as well as many items of the problem list. This is the second study, after that of Alosaimi, et al [18], that utilizes the Arabic version of the DT in screening a large number of patients with different types of cancer for emotional distress. The NCCN introduced the DT as a screening tool to identify sources of distress at the initial visit soon after diagnosis and at each visit, though the screening schedule may be judged as clinically indicated [2]. The DT is a single-item tool using a zero (no distress) to 10 (extreme distress)-point Likert scale resembling a thermometer. The patient rates his/her level of distress over the past week [2,9]. The NCCN Problem List for patients is a 39-item supplemental list of potential sources of distress that is incorporated as an essential part of the assessment to assist the provider in identifying distress. As this PL provides a comprehensive list of categories, including practical, family, physical, and emotional problems, as well as spiritual/religious concerns, it covers almost all aspects that might attribute to distress among cancer patients $[2,3,9,18]$. We think that, despite the apparent simplicity of DT, it covers most-if not all-problems might be faced by any study population (i.e. populations with different racial, religious, social and financial aspects), and worldwide. So, it is not surprising that DT has been successfully translated from English into several languages [13-16, 18].

Almost half of our cohorts had a significant distress. This is in accordance with the worldwide reported prevalence rates of 20 to $52 \%$ of cancer patients [2, 9, 19] for distress among cancer patients. Particularly, our figures are very similar to that $(45.89 \%)$ reported by Hahn, et al [20].

Our study revealed that significant distress is related to age, gender, educational level, and tumor site, and stage of the disease. We enrolled a large number of patients with different types and sites of cancers, which may explain these significant associations. Despite it is thought that all cancer patients are at risk for distress, studies had identified specific risk factors like age and gender that increase the prevalence of distress among certain cancer groups. In our cohort, younger patients experienced higher levels of distress which is in agreement with previous studies [12]. Studies have shown gender differences, with reported higher levels of distress among women [12, 21, 22]. Interestingly, $56 \%$ of the current study cohort had stage IV at their initial presentation to the oncologist. Despite that this figure does not reflect advanced stage at presentation 
Table 1 Clinical and sociodemographic characteristics of the study subjects ( $n=550)$ and their association with the DT score $\geq 4^{\text {a }}$

\begin{tabular}{lllll}
\hline Characteristic & $\begin{array}{l}\text { Overall } \\
N=550(\%)\end{array}$ & $\begin{array}{l}\text { DT cut } \\
\text { off } \geq 4\end{array}$ & $\begin{array}{l}\text { DT cut } \\
\text { off }<4\end{array}$ & $P$-value \\
& & $\mathrm{N}(\%)$ & $\mathrm{N}(\%)$ & \\
\hline
\end{tabular}

Age in years

Median (range) 55 (18-85)

Gender

Male

Female

Marital Status

$\begin{array}{llll}\text { Single } & 66(12) & 30(45) & 36(55) \\ \text { Married } & 393(72) & 178(45) & 215(55) \\ \text { Divorced } & 16(3) & 8(50) & 8(50) \\ \text { Widow } & 75(13) & 38(51) & 37(49)\end{array}$

Educational level

Non-educated

Educated

$38(7)$

$25(66)$

$13(34)$

Occupation

Student
No job
Job

Monthly

Income (EP)

$<5000$
$5000-10,000$
$10,000-15,000$
$>15,000$

Health Insurance

Yes

No

108 (20)

$44(41)$

14 (47)

174 (47)

66 (44)

$83(56)$

Chronic disease

Present

Absent

$$
211(38)
$$

339 (62)

107 (51)

$147(43)$

104 (49)

Tumour Site

Head and Neck

Breast

$17(3)$

10 (59)

7 (41)

Lung

180 (33)

93 (52)

87 (48)

GIT

41 (8)

24 (59)

17 (41)

Genitourinary

127 (23)

56 (44)

71 (56)

42 (59)

Musculoskeletal

71 (13)

29 (41)

23 (79)

Haematological

29 (5)

$6(21)$

49 (58)

Type of

malignancy

Hematological

$85(15)$

36 (42)

49 (58)

Solid tumors

465 (85)

0.055
Table 1 Clinical and sociodemographic characteristics of the study subjects ( $n=550)$ and their association with the DT score $\geq 4^{\mathrm{a}}$ (Continued)

\begin{tabular}{lllll}
\hline Characteristic & $\begin{array}{l}\text { Overall } \\
\mathbf{N = 5 5 0}(\%)\end{array}$ & $\begin{array}{l}\text { DT cut } \\
\text { off } \geq \mathbf{4} \\
\mathbf{N}(\%)\end{array}$ & $\begin{array}{l}\text { DT cut } \\
\text { off }<\mathbf{4} \\
\mathbf{N}(\%)\end{array}$ & $\begin{array}{r}P \text {-value } \\
\text { Stage }\end{array}$ \\
$\quad$ Stage 1 & $29(5)$ & $6(21)$ & $23(79)$ & 0.001 \\
Stage II & $108(19)$ & $20(19)$ & $88(81)$ & \\
Stage III & $109(20)$ & $24(22)$ & $85(78)$ & \\
Stage IV & $304(56)$ & $204(67)$ & $100(33)$ &
\end{tabular}

${ }^{a} D T$ distress thermometer, EP Egyptian pound, GIT gastrointestinal. For age, data are expressed in mean \pm standard deviation and t-test with $95 \%$ confidence interval were carried out to compare age between the 2 groups of DT cut-off $<4$ and $\geq 4$. For other sociodemographic characteristics, data are expressed in numbers and percent and Chi-square tests were used to compare the significance of differences between the 2 groups of DT cut-off $<4$ and $\geq 4$

for certain tumor type, it gives an alarm about an observation that is seen in low- and middle-income countries (LMCs). In these regions, late-stage presentations can be attributed to several factors including; lack of proper health infrastructure and screening programs, limited access to health-care facilities, lack of community awareness, and social barriers impeding early detection and treatment programs [23, 24]. Interestingly, the prevalence of psychological distress differs in different cancer sites. It was observed that patients diagnosed with cancers of the breast, head and neck, colon, lung, brain, or pancreas experience greater distress [25]. On the other hand, our results contradict previous reports where no significant links between the DT and

0.209 Table 2 The most frequent problem list items among the studied patients $(n=550)$

\begin{tabular}{lll}
\hline Problems List & No. of patients & \% \\
\hline Treatment decision & 354 & 64.4 \\
Worry & 258 & 47.0 \\
Fears & 245 & 44.5 \\
Pain & 232 & 42.2 \\
Dealing with partner & 193 & 35.1 \\
Sleep & 178 & 32.4 \\
Sadness & 168 & 30.5 \\
Nausea & 156 & 28.4 \\
Eating & 156 & 28.4 \\
Depression & 147 & 26.7 \\
Constipation & 141 & 25.6 \\
Child care & 133 & 24.2 \\
Loss of interest & 129 & 23.4 \\
Sexual & 125 & 22.7 \\
Indigestion & 124 & 22.5 \\
\hline
\end{tabular}


Table 3 The association between the Distress Thermometer (DT) score $\geq 4$ and the Problems List items of 550 cancer patients

\begin{tabular}{|c|c|c|c|c|c|}
\hline Problem list & $\begin{array}{l}\text { Item Present } \\
\text { (\%) }\end{array}$ & $\begin{array}{l}\text { DT cut-off } \geq 4 \\
\text { N (\%) }\end{array}$ & $\begin{array}{l}\text { DT cut-off }<4 \\
\text { N (\%) }\end{array}$ & OR $(95 \% \mathrm{Cl})$ & Adjusted OR (95\% Cl) \\
\hline Child care & $133(24)$ & $63(47)$ & $70(53)$ & $0.9(0.623-1.362)$ & \\
\hline Housing & $124(22)$ & $64(52)$ & $60(48)$ & $0.7(0.496-1.106)$ & \\
\hline Health Insurance & $108(20)$ & $44(41)$ & $64(59)$ & $1.3(0.543-1.866)^{*}$ & $7.6(0.042-18.029)^{* * *}$ \\
\hline Transportation & $111(20)$ & $53(48)$ & $58(53)$ & $0.9(0.598-1.377)$ & \\
\hline Work and school & $36(6)$ & $20(56)$ & $16(44)$ & $1.2(0.333-1.299)$ & \\
\hline Treatment decisions & $354(64)$ & $164(47)$ & $190(53)$ & $0.9(0.655-1.340)$ & \\
\hline Dealing with children & $125(23)$ & $58(46)$ & $67(54)$ & $0.9(0.655-1.477)$ & \\
\hline Dealing with Partner & $194(35)$ & $99(51)$ & $95(49)$ & $0.7(0.514-1.039)$ & \\
\hline Ability to have children & $87(16)$ & $43(49)$ & $44(51)$ & $0.8(0.532-1.332)$ & \\
\hline Family Health Issue & $74(13)$ & $44(59)$ & $30(41)$ & $1.4(0.322-1.171)^{*}$ & \\
\hline Depression & $147(27)$ & $132(90)$ & $15(10)$ & $8.8(0.027-3.458)^{* * *}$ & $6.9(0.067-19.390)^{* * *}$ \\
\hline Fear & $245(45)$ & $178(73)$ & $67(27)$ & $2.6(0.082-1.731)^{* * *}$ & $3.9(0.134-13.690)^{* * *}$ \\
\hline Nervousness & $126(23)$ & $84(67)$ & $42(33)$ & $2.0(0.216-1.696)^{* * *}$ & \\
\hline Sadness & $168(31)$ & $136(81)$ & $32(19)$ & $4.2(0.066-2.277)^{* * *}$ & $2.0(0.260-7.020)^{* *}$ \\
\hline Worry & $258(47)$ & $178(69)$ & $80(31)$ & $2.2(0.017-1.874)^{* * *}$ & $4.4(0.089-14.021)^{* * *}$ \\
\hline Loss of interest in usual activity & $129(23)$ & $104(80)$ & $25(20)$ & $4.1(0.081-2.518)^{* * *}$ & $3.1(0.157-11.310)^{* * *}$ \\
\hline Religious & $24(4)$ & $21(88)$ & $3(12)$ & $7.0(0.033-2.412)^{* * *}$ & \\
\hline Appearance & $100(18)$ & $67(67)$ & $33(33)$ & $2.0(0.218-1.525)^{* * *}$ & \\
\hline Bathing and Dressing & $66(12)$ & $44(67)$ & $22(33)$ & $2.0(0.219-1.519)^{* * *}$ & \\
\hline Breathing & $101(18)$ & $61(61)$ & $40(39)$ & $1.5(0.313-1.163)^{*}$ & \\
\hline Change in urination & $83(15)$ & $39(47)$ & $44(53)$ & $0.8(0.593-1.511)$ & \\
\hline Constipation & $141(26)$ & $70(50)$ & $71(50)$ & $0.9(0.554-1.193)$ & \\
\hline Diarrhea & $80(14)$ & $49(61)$ & $31(39)$ & $1.5(0.304-1.190)^{*}$ & \\
\hline Eating & $156(28)$ & $87(56)$ & $69(44)$ & $1.2(0.312-1.245)$ & \\
\hline Fatigue & $269(49)$ & $163(61)$ & $106(39)$ & $1.5(0.299-1.156)^{*}$ & \\
\hline Feeling Swollen & $113(21)$ & $77(68)$ & $36(32)$ & $2.1(0.201-1.603)^{* * *}$ & \\
\hline Fever & $71(13)$ & $50(70)$ & $21(30)$ & $2.3(0.178-1.764)^{* * *}$ & \\
\hline Getting Around & $91(17)$ & $62(68)$ & $29(32)$ & $2.1(0.205-1.586)^{* * *}$ & \\
\hline Indigestion & $125(23)$ & $75(60)$ & $50(40)$ & $1.5(0.317-1.149)^{*}$ & \\
\hline Memory and Concentration & $98(18)$ & $54(55)$ & $44(45)$ & $1.2(0.409-0.986)$ & \\
\hline Mouth Sores & $72(13)$ & $45(62)$ & $27(38)$ & $1.7(0.275-1.300)^{* *}$ & \\
\hline Nausea & $156(28)$ & $98(63)$ & $58(37)$ & $1.7(0.259-1.351)^{* *}$ & \\
\hline Dry Nose \&Congestion & $74(13)$ & $40(54)$ & $34(46)$ & $1.1(0.425-1.142)$ & \\
\hline Pain & $232(42)$ & $143(62)$ & $89(38)$ & $1.6(0.228-1.477)^{* * *}$ & \\
\hline Sexual & $125(23)$ & $72(57)$ & $53(43)$ & $1.3(0.361-0.810)$ & \\
\hline Itching and Dry Skin & $86(16)$ & $44(51)$ & $42(49)$ & $1.0(0.491-1.231)$ & \\
\hline Tingling sensation in hands and feet & $98(18)$ & $52(53)$ & $46(47)$ & $1.1(0.453-1.088)$ & \\
\hline Substance Abuse & $35(6)$ & $31(89)$ & $4(11)$ & $9.0(0.034-3.411)^{* * *}$ & \\
\hline Sleep & $178(32)$ & $129(72)$ & $49(28)$ & $2.6(0.127-1.998)^{* * *}$ & $3.6(0.155-12.921)^{* * *}$ \\
\hline
\end{tabular}

OR Odds Ratio, $\mathrm{Cl}$ confidence interval

${ }^{*} P$-value $<0.05,{ }^{* *} p<0.01,{ }^{* * *} p<0.001$ 
sociodemographic and clinical characteristics were found $[3,13,15,18]$. These different findings could be contributed to differences in the study populations, ethnic groups, numbers, and types of cancer among different studies. The most frequent problems reported on the practical domain of the PL were, treatment decision (64.4\%), worry (47\%), fears (44.5\%), and pain (42.2\%).

These encountered problems are similar to the ones found by Alosaimai and co-workers [18] which could be explained by the cultural and emotional demographics similarities between the two studied Arabian populations. Even more, these encountered problems are the most challenging to the clinicians in their daily practice. It is though that the relation between dissatisfaction with the treatment decision and the experienced distress is bidirectional [26]. Hence, to alleviate treatment decision related distress, it is preferable to provide the patients with full prognostic information, treatment plans, possible adverse effects and respect their future expectations [27].

The results of this study had highlighted the importance of early screening cancer patients (at their initial diagnosis with cancer) for distress. We have seen that participants who scored 4 or more on the DT described extra problems in the practical, family, emotional, spiritual/religious and physical areas (23 out of 36 problems) than patients who scored below this cut-off score. Although degrees vary, this finding suggests that a wide range of problems contributes to distress in cancer patients [28], which is again consistent with many similar studies performed worldwide, and among various cancer populations $[11-14,18,28]$. Despite that further analysis had identified the presence of only 7 out of 36 problems, as independent factors associated with significant distress in our cohort, still this is considered a large number of problems for a cancer patient to challenge.

These findings are very similar to those observed by Alosaimi, et al [18], while they are quite different from those reported by McFarland, et al [28] who stated that only three factors were significantly associated with distress (breathing problem, eating, and nausea). This agreement with Alosaimi, et al [18] is attributed to the fact that both studies recruited Arabian population with nearly similar cultural, spiritual and emotional factors. Notably, financial and emotional concerns were prominent issues among our cohort. We had observed prominent anxiety depression symptoms (depression, fear, nervousness, sadness and worry). Finding of such problems confirms the importance of implementing "routine" screening of cancer patients for emotional distress in our society. Sleep disturbances are quite common among cancer patients, ranging from 25 to $59 \%[6,18,19]$. Consequently, these disturbances may lead to poor quality of life, compliance to treatment and hence the development of depressive stigmata $[18,19]$.

In comparison, the contrary with McFarland et al [28] could be explained by the differences in patients' numbers and cancer type between the two studies. We included a wide range of malignancies, while they included only patients with breast cancer.

In essence, barriers to screening for distress exist and they should be taken into consideration while implementing a screening program for distress [29]. Simply, patients may have misunderstanding about what the word "distress" means and to what extent it ranges [30]. Screening through the prior 1 week may be not sufficient for some patients to experience their distress. Patient barriers to screening include cultural differences as well as literacy [31]. Unfortunately, $49 \%$ of our study cohorts had low education levels (illiteracy and primary school education). Institutional barriers may include lack of privacy for screening, insufficient time and training, poor documentation of results, and lack of resources for patient referrals [30-32].

Overall, findings of the current study confirm the importance of "routine" screening of cancer patients for emotional distress. Also, they support the importance of early recognition of distress among cancer patients that comes from the possibility of overcoming its hazardous sequelae. These sequelae are difficulty in taking a treatment decision, noncompliance with cancer treatment, frequent unneeded medical visits to caregivers, more pressure on the treating team [4, 9] and more hospitalization [33]. Moreover, in some studies, it has a negative impact on survival [34]. It is well known that screening programs improve patient outcomes only when linked to an effective system of assessment and treatment. Therefore, cancer centres should implement DT screening only after developing a plan for the timely evaluation of distress, reviewing its results and managing patients whose scores suggest clinically significant distress, including making appropriate referrals based on the problem areas specified on the PL [8].

Being the first multicenter study with a large number of patients of different types of cancer does not guarantee that it has no limitations. Possible limitations include possible bias from including many types of cancers and possible convenience sampling which may affect the generalizability of the study findings to all cancer patients in Egypt.

\section{Conclusion}

The study found that almost half of Egyptian newly diagnosed cancer patients reported significant distress. This distress was significantly related to age, gender and stage of cancer at presentation. Patients who scored 4 or more on the DT described additional problems in the 
practical, family, emotional, and physical areas than patients who scored below this cut-off score. We recommend the routine use of DT for screening Egyptian patients with cancer, as well as the involvement of the psycho-oncology and social services at the time of initial diagnosis. Further multicenter studies are warranted to explore this phenomenon.

\section{Abbreviations}

DT: Distress thermometer; ECOG: Eastern Cooperative Oncology Group; LMCs: Low- and middle-income countries; NCCN: National Comprehensive Cancer Network; PL: Problem list; TNM: Tumor-node-metastasis

\section{Acknowledgements \\ Not applicable.}

\section{Authors' contributions}

All authors have provided approval of the manuscript to be published. N.A. and S.M. contributed to the draft of the submitted article, revised it critically for important content, and made substantial contributions to conception and design, as well as data acquisition, analysis, and interpretation; Sallah Khallaf (S. K. [1]), W.A. G. E, O.A., M.A. and S.K. (2) contributed to the draft of the submitted article and made substantial contributions to acquisition, and data analysis, A.A. and E.K. contributed to the draft of the submitted article and made substantial contributions to acquisition, analysis, and interpretation of physiologic data. N.A. S.K.(1), and S.M. wrote the manuscript.

\section{Funding}

This research did not receive any specific grant from funding agencies in the public, commercial, or not-for-profit sectors.

\section{Availability of data and materials}

The datasets used and/or analyzed during the current study are available from the corresponding author on reasonable request.

\section{Ethics approval and consent to participate}

The study was approved by the Ethical Committee of AUH and SECI. Written informed consent was obtained from each subject before participation.

\section{Consent for publication}

Not applicable.

\section{Competing interests}

The authors have no competing interests.

\section{Author details \\ 'Department of Medical Oncology, South Egypt Cancer Institute, Assiut University, Assiut, Egypt. ${ }^{2}$ Hematology-Oncology Department, King Khaled University hospital, King Saud University, Riyadh, Kingdom of Saudi Arabia. ${ }^{3}$ Department of Clinical Oncology, Faculty of Medicine, Mansura University, Mansura, Egypt. ${ }^{4}$ Department of Adult Hematology/Internal Medicine, Ain Shams University, College of Medicine, Cairo, Egypt. ${ }^{5}$ Department of Clinical Oncology, Faculty of medicine, Assiut University, Assiut, Egypt. ${ }^{6}$ Department of Internal Medicine, Clinical Hematology Unit/Unit of Bone Marrow Transplantation, South Egypt Cancer Institute, Assiut University, Assiut, Egypt. 'Department of Medical Physiology, Faculty of Medicine, Assiut University, Assiut, Egypt. ${ }^{8}$ Department of Pyschiatry, Faculty of Medicine, Assiut University, Assiut, Egypt. 'Department of Chest Diseases and Tuberculosis, Faculty of Medicine, Assiut University, Assiut, Egypt.}

Received: 13 April 2020 Accepted: 22 September 2020

Published online: 27 October 2020

\section{References}

1. Ibrahim AS, Khaled HM, Mikhail NNH, Baraka H, Kamel H. Cancer incidence in Egypt: results of the National Population-Based Cancer Registry Program. J Cancer Epidemiol. 2014;2014:437971. https://doi.org/10.1155/2014/437971.
2. Riba MB, Donovan KA, Andersen B. Distress management, version 3.2019, NCCN clinical practice guidelines in oncology. J Natl Compr Cancer Netw. 2019;17(10):1229-49. https://doi.org/10.6004/jnccn.2019.0048.

3. Holland JC, Anderson B, Breibart WS, Buchmann LO, Compas B, Deshields $T L$, et al. Distress management: Clinical practice guidelines in oncology. J Natl Compr Cancer Netw NCCN. Harborside Press, LLC; 2013; 11: 190-209. https://doi.org/10.6004/JNCCN.2013.0027.

4. Bultz BD, Holland JC. Emotional distress in patients with cancer: the sixth vital sign. Community Oncol. 2006;3:311-4.

5. Söllner W, DeVries A, Steixner E, Lukas P, Sprinzl G, Rumpold G, et al. How successful are oncologists in identifying patient distress, perceived social support, and need for psychosocial counselling? Br J Cancer. 2001;84:17985. https://doi.org/10.1054/bjoc.2000.1545 PMID: 11161373.

6. Carlson LE, Waller A, Mitchell AJ. Screening for distress and unmet needs in patients with cancer: Review and recommendations. J Clin Oncol. 2012:1160-77. https://doi.org/10.1200/JCO.2011.39.5509 PMID: 22412146.

7. Mitchell AJ, Kaar S, Coggan C, Herdman J. Acceptability of common screening methods used to detect distress and related mood disorders? preferences of cancer specialists and non-specialists. Psychooncology. 2008; 17:226-36. https://doi.org/10.1002/pon.1228 PMID: 17575565.

8. Mitchell AJ. Short screening tools for cancer-related distress: a review and diagnostic validity meta-analysis. J Natl Compr Cancer Netw. 2010;8(4):48794. https://doi.org/10.6004/jnccn.2010.0035.

9. Pirl WF, Fann JR, Greer JA, Braun I, Deshields T, Fulcher C, et al. Recommendations for the implementation of distress screening programs in cancer centers: Report from the American Psychosocial Oncology Society (APOS), Association of Oncology Social Work (AOSW), and Oncology Nursing Society (ONS) joint task force [Internet]. Cancer. 2014:2946-54. https://doi.org/10.1002/cncr.28750 PMID: 24798107.

10. Roth AJ, Kornblith AB, Batel-Copel L, Peabody E, Scher HI, Holland JC. Rapid screening for psychologic distress in men with prostate carcinoma: a pilot study. Cancer. 1998;82:1904-8 Available: http://www.ncbi.nlm.nih.gov/ pubmed/9587123 PMID: 9587123

11. Graves KD, Arnold SM, Love CL, Kirsh KL, Moore PG, Passik SD. Distress screening in a multidisciplinary lung cancer clinic: Prevalence and predictors of clinically significant distress. Lung Cancer. 2007;55:215-24. https://doi.org/ 10.1016/j.lungcan.2006.10.001 PMID: 17084483.

12. Hegel MT, Moore CP, Collins ED, Kearing S, Gillock KL, Riggs RL, et al. Distress, psychiatric syndromes, and impairment of function in women with newly diagnosed breast cancer. Cancer. 2006;107:2924-31. https:/doi.org/ $10.1002 /$ cncr.22335.

13. Hoffman B, Zevon M, D'Arrigo M, Cecchini T. Screening for distress in cancer patients: the NCCN rapid-screening measure. Psychooncology. 2004; 13:792-9.

14. van Dooren S, Duivenvoorden HJ, Passchier J, Bannink M, Tan MBM, Oldenmenger WH, et al. The Distress Thermometer assessed in women at risk of developing hereditary breast cancer. Psychooncology. 2009;18:108087. https://doi.org/10.1002/pon.1451. PMID: 12733160.

15. Akizuki N, Akechi T, Nakanishi T, Yoshikawa E, Okamura M, Nakano T, et al. Development of a brief screening interview for adjustment disorders and major depression in patients with cancer. Cancer. 2003;97:2605-13. https:// doi.org/10.1002/cncr.11358.

16. Ozalp E, Cankurtaran ES, Soygur H, Ozdemir Geyik P, Jacobsen PB. Screening for psychological distress in Turkish cancer patients. Psychooncology. 2007; 16:304-11. https://doi.org/10.1002/pon.1059.

17. Gil F, Grassi L, Travado L, Tomamichel M, Gonzalez JRR. Southern European Psycho-Oncology Study Group. Use of distress and depression thermometers to measure psychosocial morbidity among southern European cancer patients. Support Care Cancer. 2005;13:600-6. https://doi. org/10.1007/s00520-005-0780-0.

18. Alosaimi FD, Abdel-Aziz N, Alsaleh K, Al Sheikh R, Al Sheikh R, Abdel-Warith A. Validity and feasibility of the Arabic version of distress thermometer for Saudi cancer patients. PLoS ONE. 2018;13(11):e0207364. https://doi.org/10. 1371/journal.pone.0207364.

19. Mehnert A, Hartung TJ, Friedrich M, et al. One in two cancer patients is significantly distressed: prevalence and indicators of distress. Psychooncology. 2018;27:75-82.

20. Hahn C, Joo SH, Chae JH, Lee CU, Kim TS. Feasibility of Psychosocial Distress Screening and Management Program for Hospitalized Cancer Patients. Psychiatry Investig. 2017;14(6):734-45. 
21. Jacobsen PB, Donovan KA, Trask PC, Fleishman SB, Zabora J, Baker F, et al. Screening for psychologic distress in ambulatory cancer patients. Cancer. 2005;103:1494-502. https://doi.org/10.1002/cncr.20940.

22. Shim E-J, Shin Y-W, Jeon HJ, Hahm B-J. Distress and its correlates in Korean cancer patients: pilot use of the distress thermometer and the problem list. Psychooncology. 2008;17:548-55. https://doi.org/10.1002/pon.1275.

23. Smith RA, Caleffi M, Albert US, Tony CHH, Duffy SW, Franceschi D, et al. Breast cancer in limited resource countries: early detection and access to care. Breast J. 2006;12(Suppl 1):S16-26. https://doi.org/10.1111/j.1075-122X. 2006.00200.x.

24. Stapleton JM, Mullan PB, Dey S, Hablas A, Gaafar R, Seifeldin IA, et al. Patient-mediated factors predicting early- and late-stage presentation of breast cancer in Egypt. Psychooncology. 2011;20(5):532-7. https://doi.org/10, 1002/pon.1767.

25. Zabora J, Brintzenhofe Szoc K, Curbow B, Hooker C, Piantadosi S. The prevalence of psychological distress by cancer site. Psychooncology. 2001; 10(1):19-28. https://doi.org/10.1002/1099-1611(200101/02)10:1<19::aidpon501>3.0.co;2-6

26. Budden LM, Hayes BA, Buettner PG. Women's decision satisfaction and psychological distress following early breast cancer treatment: A treatment decision support role for nurses. Int J Nurs Pract. 2014;20:8-16. https://doi. org/10.1111/ijn.12243.

27. Bernacki RE, Block SD. Communication About Serious IIIness Care Goals. American Medical Association; JAMA Intern Med. 2014;174:1994. https://doi. org/10.1001/jamainternmed.2014.5271.

28. McFarland DC, Jutagir DR, Miller A, Nelson C. Physical problem list accompanying the distress thermometer: Its associations with psychological symptoms and survival in patients with metastatic lung cancer. PsychoOncology. 2020. https://doi.org/10.1002/pon.5367.

29. Olson SL, Law MJ, Brodeur PD, Salerno AC, Thomas A, McMillan CS, et al. Relationship With God, Loneliness, Anger, and Symptom Distress in Patients With Cancer Who Are Near the End of Life. J Hosp Palliat Nurs. 2014;16:4828. https://doi.org/10.1097/NJH.0000000000000105.

30. Ownby KK. Use of the Distress Thermometer in Clinical Practice. J Adv Pract Oncol. 2019;10(2):175-9. https://doi.org/10.6004/jadpro.2019.10.2.7.

31. Mitchell A. Screening for cancer-related distress: When is implementation successful and when is it unsuccessful? Acta Oncologia. 2013;52(2):216-24. https://doi.org/10.3109/0284186X.2012.745949.

32. Lo SB, lanniello L, Sharma M, Sarnacki D, Finn KT. Experience implementing distress screening using the National Comprehensive Cancer Network distress thermometer at an urban safety-net hospital. Psycho-Oncology. 2016;25(9):1113-5. https://doi.org/10.1002/pon.4214.

33. Nipp RD, El-Jawahri A, Moran SM, et al. The relationship between physical and psychological symptoms and health care utilization in hospitalized patients with advanced cancer. Cancer. 2017;123:4720-7.

34. Kissane D. Beyond the psychotherapy and survival debate: the challenge of social disparity, depression and treatment adherence in psychosocial cancer care. Psychooncology. 2009;18:1-5.

\section{Publisher's Note}

Springer Nature remains neutral with regard to jurisdictional claims in published maps and institutional affiliations.

Ready to submit your research? Choose BMC and benefit from:

- fast, convenient online submission

- thorough peer review by experienced researchers in your field

- rapid publication on acceptance

- support for research data, including large and complex data types

- gold Open Access which fosters wider collaboration and increased citations

- maximum visibility for your research: over $100 \mathrm{M}$ website views per year

At $\mathrm{BMC}$, research is always in progress.

Learn more biomedcentral.com/submissions 